\title{
Exploring Readiness and Commitment of Senior Management towards Public Sec- tor Transformational Change: A Rasch Analysis
}

\author{
${ }^{1}$ Nazirah Aziz ${ }^{2}$ Wee Shu Hui ${ }^{3}$ Zamalia Mahmud \\ ${ }^{12}$ Accounting Research Institute, Faculty of Accountancy, \\ Universiti Teknologi MARA, 40450 Shah Alam, Selangor, MALAYSIA \\ ${ }^{3}$ Centre of Statistical and Decision Science Studies, Universiti Teknologi MARA, \\ 40450 Shah Alam, , Selangor, MALAYSIA \\ ${ }^{1}$ nazirah_00@yahoo.com, ${ }^{2}$ weesh411@salam.uitm.edu.my, ${ }^{3}$ zamalia@tmsk.uitm.edu.my
}

\begin{abstract}
The purpose of this paper is to provide empirical evidence on the perceived readiness of managers towards public sector transformational change. Data was collected using digital questionnaire from 40 managers in various public sector organisations. Data was analysed using Rasch measurement and Winsteps ${ }^{\circledR}$ 3.72.3. The study shows that the public sector managers highly recognize the role and commitment of the senior management as an important driver towards successful implementation of change.
\end{abstract}

Keywords: Public Sector Change;

Readiness for Transformation;

Commitment of Senior Management;

Rasch Measurement Model.

\section{Introduction}

Globalisation has placed strong pressure on government to compete for trade flows, investment and resources [1] \& [2]. Since the early 1980s, the Government of Malaysia has taken a lot of initiatives to drive reform and replace the traditional administration structures [3] [4] \& [5]. The New Public Management (NPM) has been introduced to solve the problem of inefficiency with its emphasis on managing outcomes and results as one of the ways to improve performance in public sector [4] \& [5]. [1] further points out that it is important to have a high quality and excellent public sector delivery system as poor delivery system can damage investors' confidence to do business and invest in Malaysia.

The Prime Minister of Malaysia, Datuk Seri Mohd Najib in his Cabinet Appointment speech on 1 April 2009, he emphasises a new concept called "1 Malaysia: People First, Performance Now" as the new administrations tag line. This indicates that the government is seriously focusing on improving performance towards achieving Vision 2020. Performance management is the key agenda in public sector organisations on the basis that it will help them meet improvement targets. In 2009, Performance Management and Delivery Unit (PEMANDU) was established to "oversee the implementation and assess progress of the Government Transformation Programme (GTP) and Economic Transformation Program (ETP), facilitate as well as support delivery of both the National Key Result Areas (NKRAs), and National Key 
Economic Areas (NKEAs)". In addition, the role of PEMANDU is also to support the Unity and Performance Minister in implementing the Key Performance Indicators (KPIs) system. The aim of establishing GTP is to improve public services and helping the government to achieve the ideals of 1Malaysia, while the ETP is focusing more on sustainable initiative that will transform Malaysia into a high income nation by 2020 [5].

Resistance to change will lead to great losses in government, and change is often resisted. It has been reported that the government has spend almost 66 million in setting up PEMANDU to lead the transformation. This includes the cost of engaging external consultants and establishing 1Malaysia lab to bring all parties from public sector, private sector and academicians together to discuss the best ways and alternatives of transforming Malaysian public sector. The [1] stressed on the importance of improving public sector delivery services to enhance investor's confidence. It is believed that successful transformation will lead to improve in public service delivery and enhancing investors' confidence. Moreover, reluctance to change will consequently affect the public at large.

\section{Previous Research}

\subsection{Readiness for transformation}

Transformation can be defined as"change in form, appearance or structure" [6] (p.1). The authors suggested that transformation occurs first at the individual level, and then, at the organisational level. The readiness of individuals working in an organisation reflects the readiness of organisation towards transformation. Individual readiness is an important driver for successful change in an organisation [7] $\&[8]$.

Transformation denotes not only members' belief in subscribing to change, but also members actively engaging in practices that will lead to its successful implementation [8] \& [9]. [9] further added that the announcement of transformation is not sufficient enough to persuade employees that organisation is ready to implement the change. If the organisation failed to persuade or ensure that the change is needed, then the employees might feel that the organisation may fail to change [3] \& [9].

Prior researchers had attempted to identify the underlying reasons that caused failure in organisational change. [10] addressed that it is important to understand the causes of failure and drive for success in managing organisational change. It is important to have the right people to lead the organization, leaders with skills, competencies and aptitude to implement the guidelines for successful change. ${ }^{[11]}$ conducted a study on the role of internal communication and employee development towards readiness to change. The authors found that poor communication was seen as a key driver of negative feelings among the staffs towards change. Employees feel that the senior management team did not have a clear vision, and the communication about change was not open and honest [11].

\subsection{Commitment of Senior Manage- ment towards Change}

This study proposed that commitment of senior management is an important driver of readiness for transformation. [9] pointed out that there must be a champion of transformation at the most senior level, a decisive and confident leader who can articulate organisational goals, priorities and strategies concerning change. Senior management is responsible to define the course of change to their subordinates, and demonstrate their commitment to transformation through their behaviours. Moreover, senior managers are responsi- 
ble for taking an overview of the presents and future direction and activities of their organisations [10]. Hence, organisations that want to be perceived by their employees to be ready for the transformation should pay close attention to the commitment of senior management.

\section{Study Design and Methods}

This study used a survey method to gather information from 40 managers working in various public sector organizations using convenience sampling. Managers were assessed on their perceived readiness towards change where they need to respond to nine items based on a 5-point Likert scale ranging from (1) strongly disagree to (5) strongly agree. Data collection process was conducted between July and August 2012 using online digital questionnaire. The questionnaire was improvised based on feedback from the content experts and was subjected to reliability and validity analysis using selected Rasch measurement tools via the WINSTEPS $^{@} 3.72 .3$ software.

The Rasch measurement is based on a probabilistic model which originates from the Linear Hierarchical Logistic Model [11]. In the Rasch philosophy, the data have to comply with the principles, or in other words, the data has to fit the model. From Rasch point of view, it is required to test whether the data allow for measurement on a linear interval scale specifically in a cumulative response process [11].

Based on the Rasch rating scale model, we will estimate $P_{n i l}$, the probability of person $\mathrm{n}$ choosing "disagree" (category 2) over "strongly disagree" (category 1 ) on any item $(i) . D_{i}$ is the difficulty of item $i$ and $F_{1}$ is the difficulty of the first threshold on item $(i)$. The rating scale model is illustrated in Eq. (1):

$$
P_{n i 1}\left(x=1 / B_{n}, D_{i}, F_{1}\right)=\frac{e^{\left(B-\left[D_{i}+F_{1}\right]\right)}}{1+e^{\left(B-\left[D_{i}+F_{1}\right]\right)}}
$$

\section{Analysis and Results}

\subsection{Assessing Quality of Data}

Table 1 illustrates overall information about whether the data showed acceptable fit to the model. The mean infit and outfit for person and item mean squares are expected to be 1.0. As can be seen from Table 1 , the mean infit and outfit are 0.83 and 0.87 respectively; while Table 2 illustrates the mean infit and outfit for items are 0.98 and 0.87 respectively. The mean standardized infit and outfit are expected to be 0.0 and here they are -.6 for person and 0.0 for items. The standard deviation of the standardized infit is an index of overall misfit for persons and items. Using 2.0 as a cut-off criterion [13], both persons (standardized infit standard deviation $=1.54$ ) and items (standardized infit standard deviation $=.29$ ) show an overall acceptable fit.

Separation is the index of spread of the person positions or items positions. If separation is 1.0 or below, the items may not have sufficient breadth in position [12]. For persons, separation is 2.35 for the data at hand (real), and is 6.17 when the data has no misfit to the model (model). High separation index represent a large spread of items and persons along the continuum. The item separation index is 0.85 which is lower than for persons.

Separation determines reliability of items and persons [12]. Higher separation in concert with variance in person or item position yields higher reliability. The person separation reliability estimate for this data is 0.85 while the item separation reliability estimate is 0.42 . Low item reliability indicates that the sample is not big enough to precisely locate the items on the latent variable. Item reliability can increase with bigger sample size and produce stable item estimates. This estimate is expected to increase when more samples are gathered to produce a more reliable item estimate. 
Table 1 Summary of Person Measure

\begin{tabular}{|c|c|c|c|c|c|c|c|c|}
\hline & $\begin{array}{l}\text { Raw } \\
\text { Scor } \\
\text { e }\end{array}$ & $\begin{array}{l}\text { Coun } \\
t\end{array}$ & $\begin{array}{l}\text { Meas } \\
\text { ure }\end{array}$ & $\begin{array}{l}\text { Mo } \\
\text { del } \\
\text { er- } \\
\text { ror }\end{array}$ & $\begin{array}{l}\text { In } \\
\text { MNSQ } \\
\text { ZStd }\end{array}$ & & $\begin{array}{l}\text { Out } \\
\text { MNSQ } \\
\text { ZStd }\end{array}$ & \\
\hline $\begin{array}{l}\text { Mea } \\
n\end{array}$ & 33.1 & 8.9 & 1.02 & 0.96 & 0.83 & $\begin{array}{l}-.6 \\
\end{array}$ & $\begin{array}{l}0.8 \\
7\end{array}$ & $-\overline{6}$ \\
\hline S.D & 4.7 & .2 & 2.90 & 0.15 & 1.54 & 1.7 & $\begin{array}{l}1.5 \\
7\end{array}$ & $\begin{array}{l}1 . \\
7\end{array}$ \\
\hline Max & 41.0 & 9.0 & 6.20 & 1.21 & 7.46 & 4.1 & $\begin{array}{l}7.2 \\
3\end{array}$ & $\begin{array}{l}3 . \\
6\end{array}$ \\
\hline Min & 18.0 & 8.0 & -6.87 & 0.70 & 0.02 & -2.2 & $\begin{array}{l}0.0 \\
2\end{array}$ & - \\
\hline \multicolumn{2}{|c|}{$\begin{array}{l}\text { Real RMSE } \\
1.13 \\
\text { Model RMSE } \\
0.97\end{array}$} & \multicolumn{2}{|c|}{ Adj. SD 2.73} & $\begin{array}{l}\text { Sepa } \\
2.35 \\
\text { Sepa } \\
2.82\end{array}$ & & \multicolumn{3}{|c|}{$\begin{array}{l}\text { Person Reliability } \\
0.85 \\
\text { Person Reliability } \\
0.89\end{array}$} \\
\hline
\end{tabular}

Table 2 Summary of Item Measure

\begin{tabular}{|c|c|c|c|c|c|c|c|c|}
\hline & \multirow{2}{*}{$\begin{array}{l}\text { Raw } \\
\text { Score }\end{array}$} & \multirow[b]{2}{*}{ Count } & \multirow[b]{2}{*}{$\begin{array}{l}\text { Mea } \\
\text { sure }\end{array}$} & \multirow{2}{*}{$\begin{array}{l}\text { Mod } \\
\text { el } \\
\text { error }\end{array}$} & \multicolumn{2}{|c|}{ Infit } & \multicolumn{2}{|c|}{ Outfit } \\
\hline & & & & & MNSQ & ZStd & \multicolumn{2}{|c|}{$\begin{array}{l}\text { MNSQ } \\
\text { ZStd }\end{array}$} \\
\hline $\begin{array}{l}\mathrm{Me} \\
\text { an }\end{array}$ & 132.6 & 35.8 & 0.00 & 0.46 & .98 & 0.0 & 0.87 & - \\
\hline $\begin{array}{l}\text { S. } \\
\text { D }\end{array}$ & 4.2 & 0.4 & 0.64 & 0.02 & 0.29 & 0.8 & 0.18 & 4 \\
\hline $\begin{array}{l}\text { Ma } \\
x\end{array}$ & 137.0 & 36.0 & 1.28 & 0.48 & 1.53 & 1.4 & 1.19 & 6 \\
\hline $\begin{array}{l}\mathrm{Mi} \\
\mathrm{n}\end{array}$ & 123.0 & 35.0 & -.82 & 0.42 & 0.59 & -1.1 & 0.66 & - \\
\hline \multicolumn{2}{|c|}{$\begin{array}{l}\text { Real RMSE } \\
0.49\end{array}$} & \multicolumn{2}{|c|}{ Adj. SD 0.41} & \multicolumn{2}{|c|}{ Separation 0.85} & \multicolumn{3}{|c|}{ Item Reliability 0.42} \\
\hline \multicolumn{2}{|c|}{$\begin{array}{l}\text { Model RMSE } \\
0.46\end{array}$} & \multicolumn{2}{|c|}{ Adj. SD 0.44} & \multicolumn{2}{|c|}{ Separation 0.95} & \multicolumn{3}{|c|}{ Item reliability 0.48} \\
\hline
\end{tabular}

\subsection{Item Fit}

Overfit is indicated by a mean square value of less than 1.0, and negative standardized fit. Overfit is interpreted as too much variation in the response pattern, perhaps indicating the presence of redundant items. Underfit is indicated by a mean square greater than 1.6 and standardized fit of less than 2.0 suggests an unusual and/or inappropriate response pattern [12].

Table 3 shows that there is one misfit item as indicated by infit and outfit values which are outside the range of 0.6 to 1.4 (items Fc_8 and Fc_9). Due to small range of item difficulty and large range of person ability, misfit cannot be precisely located on the items. Here the misfit items indicate the managers' inability to precisely perceive their attitude was due to inappropriate items thus restrict the measurement of the latent trait. The validity can be improved if similar items were removed or combined [12].

Table 3 consolidated item misfit

IENTRY
I RAW
INUMBER
I SCORE

\subsection{Unidimensionality}

Unidimensionality is crucial to assure the instrument is measuring the specific objective, in this case readiness of public sector managers towards transformation as determine by the commitment of senior management towards transformation. Rasch analysis applies the Principal Component Analysis (PCA) of the residuals; i.e how much variance is the instrument in measuring what is it supposedly to measure. The raw variance explained by measures is $66.5 \%$ closely match to the expected $65.7 \%$. Though it meets unidimensionality requirement minimum of $20 \%$.

Table 4 Standardized Residual Variance (in Eigenvalue units)

\begin{tabular}{|c|c|c|c|c|c|}
\hline & & \multicolumn{2}{|c|}{ Empirical } & \multicolumn{2}{|c|}{ Modeled } \\
\hline $\begin{array}{l}\text { Total variance } \\
\text { in observa- } \\
\text { tions }\end{array}$ & $=$ & 26.9 & $100 \%$ & & $100 \%$ \\
\hline $\begin{array}{l}\text { Variance ex- } \\
\text { plained by } \\
\text { measures }\end{array}$ & $=$ & 17.9 & $66.5 \%$ & & $65.7 \%$ \\
\hline $\begin{array}{l}\text { Unexplained } \\
\text { variance (to- } \\
\text { tal) }\end{array}$ & $=$ & 9.0 & $54.5 \%$ & $100 \%$ & $34.3 \%$ \\
\hline $\begin{array}{l}\text { Unexplained } \\
\text { variance in } 1 \mathrm{st} \\
\text { contrast }\end{array}$ & $=$ & 3.1 & $11.5 \%$ & $34.5 \%$ & \\
\hline
\end{tabular}




\subsection{Person- Item Distribution Map}

The heart of Rasch analysis is provided in Figure 1, which is the person-item distribution map. Items and persons (or respondents) share the same linear measurement units known as logits. Referring to [12], logits is a unit derived from transforming ordinal data into an interval scale.

The person-item map illustrates all and more importantly the hierarchy of difficulty order. This will be the premise of the construct validity acceptance [13]. Persons are distributed on the left side of the logit ruler and items are distributed on the right side. Those at the upper end of the scale agreed with more items and agreed more strongly. Letter " $M$ " denotes the managers" item mean, " $\mathrm{S}$ " is one standard deviation away from the mean and "T" marks two standard deviations away from the mean.

As can be seen in Figure 1, 40 managers are mapped on the left side of the map under the heading 'persons'. The distribution of respondents' positions is on the left side of the vertical dashed line in increasing order of ability. Those at the upper end of the scale agreed with more items and agreed strongly. Managers with ID number 14 and 26 are found to have agreed completely with all the items, followed closely by managers with ID number 25, 19, 23, 37. About 42.5\% (17/40) managers did not find all items to be important driver to reflect the commitment of the senior management towards transformation (ID number 22, 07, $33, \ldots 08)$.
In the map, we can see that $57.5 \%$ of the managers fall above of all 9 items. These group of managers also agreed that the senior management people in their organization pay attention to the ideas brought to them by the middle managers and employees (refer to item $\mathrm{Fc}_{-}$5).

Figure 1 reported that the readiness of managers with ID number 34, 17 and 36 matches items Fc_4 and Fc_8. This indicates that these three managers neither agree nor disagree that there is a champion of transformation at the most senior level in their organization (refer to item $\left.F c \_4\right)$. They also have a neutral agreement that the senior management team in their department is actively involved with the transformation (refer to item Fc_8).

Those managers who are mapped above Item Fc_6 agreed that all these items or constructs are important drivers to improve readiness towards transformation through commitment of the senior management.

There is also an indication of redundancy among the items as shown on the map. These items are labeled as Fc_1, Fc_2 and Fc_3. Fc_1 is measuring whether managers agree that the senior management is decisive with respect to organizational goals, priorities and strategies concerning the transformation. Fc_2 is measuring whether the senior management themselves have brought into the transformation and promote it by behaving in a manner consistent with the transformation. Item $\mathrm{Fc} \_3$ is measuring whether senior management defines the course of transformation to their subordinates. 


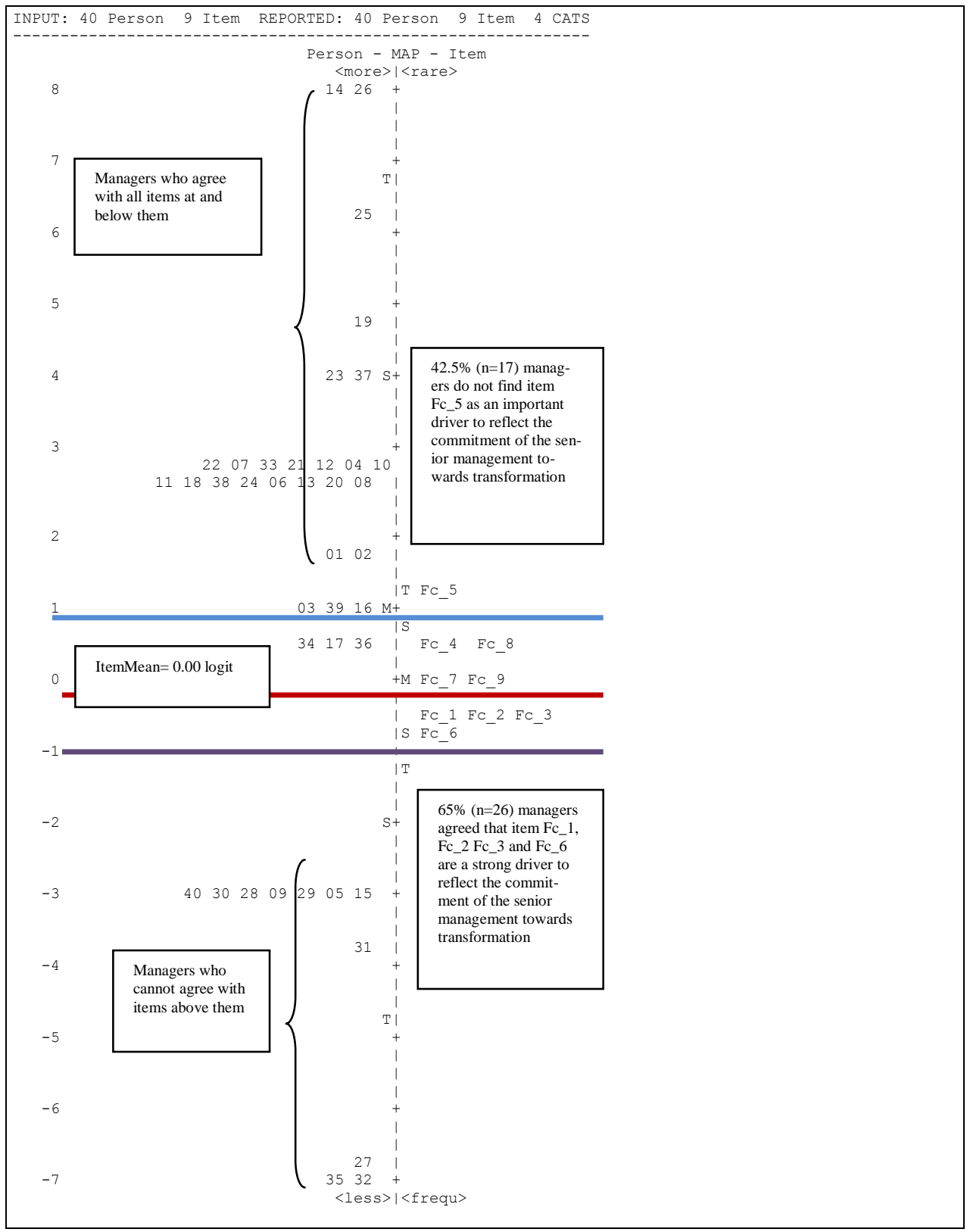

Fig. 1: Person-Item Distribution Map (PIDM) 


\section{Conclusion}

In enhancing efficiency and effectiveness in delivering public services, the Government of Malaysia has to be concerned with issues concerning continual administrative reforms. However, administrative reforms take time. This study has shown that the measurement of managers response towards readiness for transformation can be precisely measured using the Rasch probabilistic model. Most of the respondents indicated their agreement to almost every item in the dimension of commitment of senior management to the transformation. The result is consistent with the previous study where the commitment of senior management is seen as an important driver for successful transformation.

\section{References}

[1] "Auditor General report," 2007

[2] K. A.Goyal, "Impact of Globalization on Developing Countries: With Special Reference to India,"International Research Journal of Finance and Economics, vol. 5, pp. 166 - 171, 2006.

[3] M. A. Norhayati and A. K. SitiNabiha, "A case study of the performance management system in a Malaysian government linked companies," Journal of Accounting and Organisational Change, vol. 5, no. 2, pp. 243-276, 2009.

[4] N. A. Siddiquee,"Managing for results: lessons from public management reform in Malaysia", International Journal of Public Sector Management, Vol. 23 Iss: 1, pp.38 - 53, 2010.

[5] "Roadmap to Government Transformation Program,"2010. [www.pemandu.gov.my]
[6] S. M.Elias, "Employee commitment in times of change: Assessing the importance of attitudes toward organisational change," Journal of Management, vol. 35, no. 37, pp. 37-54, 2009.

[7] A. A. Armenakis and S. G.Harris, "Crafting a change message to create transformational readiness,"Journal of Organisational Change, vol. 15, no. 2, pp. 169-183, 2002.

[8] B. Burnes, "Kurt Lewin and complexity theories: back to the future?" Journal of Change Management, vol. 4, no. 4, pp. 309-325, 2004a.

[9] I. Cinite, L. E. Duxbury and C. Higgins, "Measurement of perceived organisational readiness for change in the public sector,"British Journal of Mangement, vol. 20, pp. 26- 277, 2009.

[10] B. Burnes, 'Managing change and changing managers from $\mathrm{ABC}$ to XYZ', Journal of Management Development, 22 (7), 627-642, 2003.

[11] T. Proctor and I. Doukakis, "Change management: the role of internal communication and employee development", Corporate communication: An International Journal, 8 (4), 268-277, 2003.

[12] S. Zakaria, A. Abdul Aziz, A. Mohamed, N. H. Arshad, H. Ahmad Ghulman, and M. S. Masodi, "Assessment of Information Managers' Competency using Rasch Measurement," Third International Conference on Convergence and Hybrid Information Technology, 2008.

[13] Z. Mahmud, 'Diagnosis of perceived attitude, importance, and knowledge in statistics based on rasch probabilistic model', International Journal of Applied Mathematics and Informatics, vol. 5, pp.291298, 2011. 